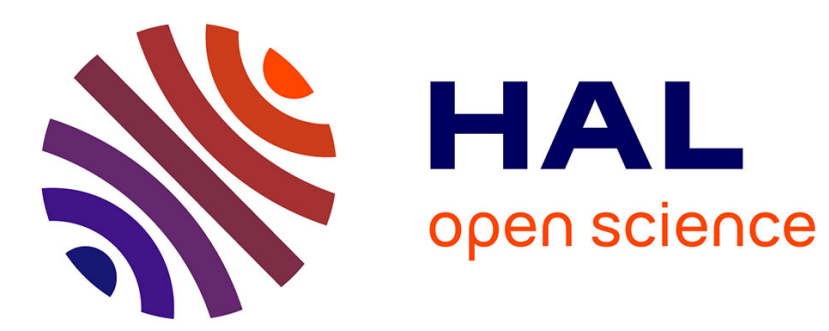

\title{
WIRELESS CHIPLESS PASSIVE MICROFLUIDIC TEMPERATURE SENSOR
}

Émilie Debourg, Ayoub Rifai, Sofiene Bouaziz, Anya Traille, Patrick Pons, Hervé Aubert, Manos Tentzeris

\section{- To cite this version:}

Émilie Debourg, Ayoub Rifai, Sofiene Bouaziz, Anya Traille, Patrick Pons, et al.. WIRELESS CHIPLESS PASSIVE MICROFLUIDIC TEMPERATURE SENSOR. Transducers, Jun 2013, Barcelone, Spain. pp.T3P.027. hal-00878252

\section{HAL Id: hal-00878252 https://hal.science/hal-00878252}

Submitted on 29 Oct 2013

HAL is a multi-disciplinary open access archive for the deposit and dissemination of scientific research documents, whether they are published or not. The documents may come from teaching and research institutions in France or abroad, or from public or private research centers.
L'archive ouverte pluridisciplinaire HAL, est destinée au dépôt et à la diffusion de documents scientifiques de niveau recherche, publiés ou non, émanant des établissements d'enseignement et de recherche français ou étrangers, des laboratoires publics ou privés. 


\title{
WIRELESS CHIPLESS PASSIVE MICROFLUIDIC TEMPERATURE SENSOR
}

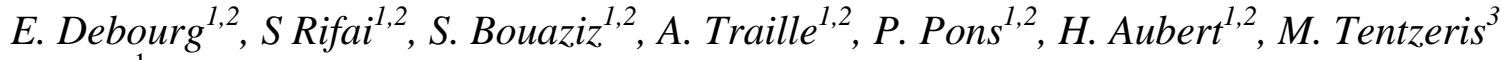 \\ ${ }^{1}$ CNRS, LAAS, 7 avenue du colonel Roche, F-31400 Toulouse, FRANCE \\ ${ }^{2}$ Univ de Toulouse, LAAS, F-31400 Toulouse, France \\ ${ }^{3}$ School of ECE, Georgia Institute of Technology, Atlanta, GA 30332, U.S.A
}

\begin{abstract}
Autonomous wireless sensors are a key technology for “Ambiant Intelligence”. For several years, chiplesselectromagnetics sensors are studied to overcome the limitations of other passive sensors like low interrogation distance.

In this paper we present a new concept of passive temperature sensor based on the electromagnetic coupling between an RF capacitor and dielectric liquid moving inside a SU8 micro-channel. The concept is validated using water as dielectric liquid with a full scale variation of S11 versus temperature around $8 \mathrm{~dB}$ at $29.75 \mathrm{GHz}$
\end{abstract}

\section{KEYWORDS}

Wireless sensor, Passive sensor, Chipless sensor, RF and microfluidic coupling

\section{INTRODUCTION}

There has been an ever growing demand for autonomous wireless sensors for many applications, especially over the last decade. Passive sensors (with no transmitter) permit a completely autonomous operation using backscattering-based methods (e.g. RFID, SAW). However, the main drawback of these sensors concerns the short reading range (typically $<10 \mathrm{~m}$ ). Recently, a new kind of passive sensors with electromagnetic transducers has been introduced throughout the world. They are based on the variability of RF impedance or resonance frequency and have several advantages (autonomy, compatibility with harsh environment, reading range greater than other passive sensors).

This new breed of sensors has been studied for numerous applications (gas, stress, pressure, temperature, air flow, cracks). For temperature sensors, two main principles based on the variability of the RF resonance have been studied: modification of electromagnetic coupling by bimorph cantilever [1-3] and variation of the substrate permittivity [4-5]. The second principle is especially interesting as its fabrication is very simple (only metal patterning on substrate is required). But its sensitivity is not very high which makes these sensors especially well adapted for a wide temperature range. The authors of this paper have recently introduced a new sensing principle coupling electromagnetics with micro fluidics using conductive liquids [6] and more recently dielectric liquid [7], thus achieving a much higher sensitivity.

This paper is focused on the design and characterization of the electromagnetic transducer using dielectric liquid for micro fluidic coupling.

\section{TRANSDUCER CONCEPT}

The transducer is based on a planar capacitor where a micro fluidic channel changes the permittivity of the medium between the two electrodes of the capacitor (Figure 1). The displacement of the fluid versus temperature inside the channel is obtained through its thermal dilation when fed through a tank whose volume is optimized to obtain the right sensitivity.

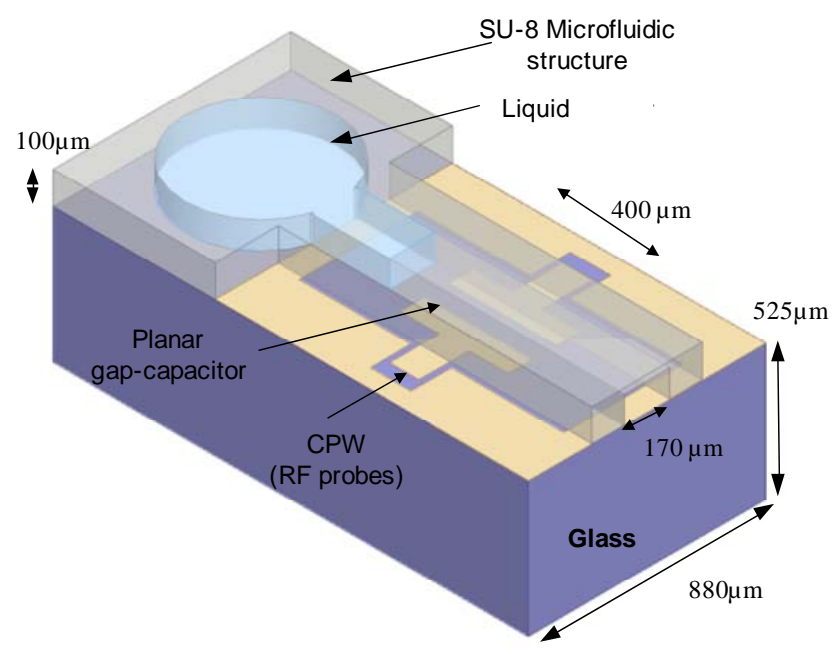

Figure 1 : Schematics of the microfluidic RF capacitor

The substrate is a Schott AF32 glass to minimize the losses and reduce interaction between the electromagnetic field and the substrate. The capacitor electrodes are fabricated with $100 \mathrm{~nm}$ thick copper. The channel is obtained by SU8 photoresist patterning and lamination of a SU8 dry-film. The dielectric fluid used for the concept validation is pure water. Even though such a liquid is not ideal for commercial sensors, it is useful from technological point of view for proof-of-concept. Preliminary results obtained with ethylene and propylene glycol will be also given in order to replace water.

The operating frequency is fixed at $29.75 \mathrm{GHz}$ to be compatible with the frequency band of the millimeterwave Radar we have developed for the wireless interrogation. An example of simulated reflection coefficient S11 is given on Figure 2, showing a decrease with water progression inside the channel. The dimension of the coplanar capacitor has been optimized relative to sensitivity (Figure 3, Figure 4). The reduction of the capacitor length down to $400 \mu \mathrm{m}$ allows obtaining a S11 full scale (between full and empty channel) shift around $9 \mathrm{~dB}$. This $400 \mu \mathrm{m}$ length is enough to guarantee good accuracy for arbitrary temperature-dependent liquid positioning inside the channel. By increasing the distance between the capacitor electrode and the ground up to 
$400 \mu \mathrm{m}$, it is also possible to maximize the sensor sensitivity. The distribution of electric field is given for the capacitor surface and along the vertical axis inside channel without water (Figure 5) and with channel fully filled with water (Figure 6). We can see that the water inside the channel favors the power transmission between the two capacitor electrodes and that $100 \mu \mathrm{m}$ thick water is enough to confine the electromagnetic field.

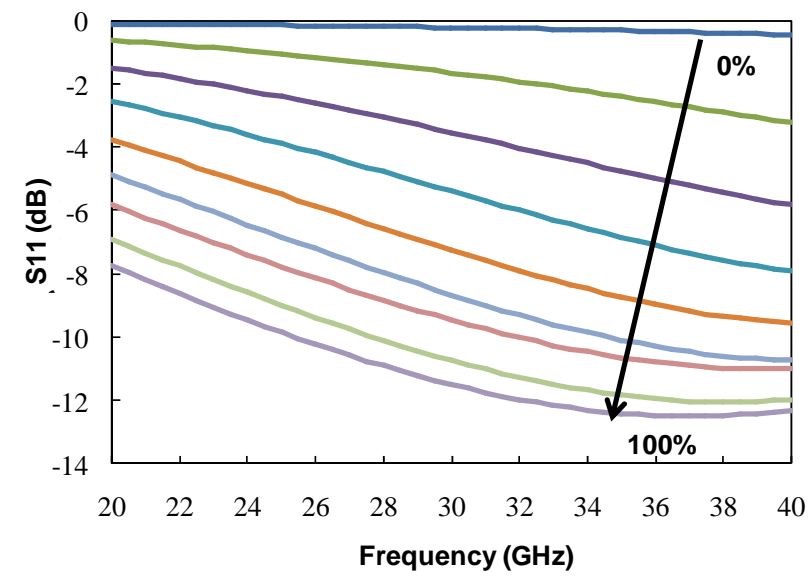

Figure 2 : Reflection coefficient versus frequency for various channel filling with water $(0 \%, 12.5 \%, 25 \%$, $37.5 \%, 50 \%, 62.5 \%$, 75\%, 87.5\%, 100\%)

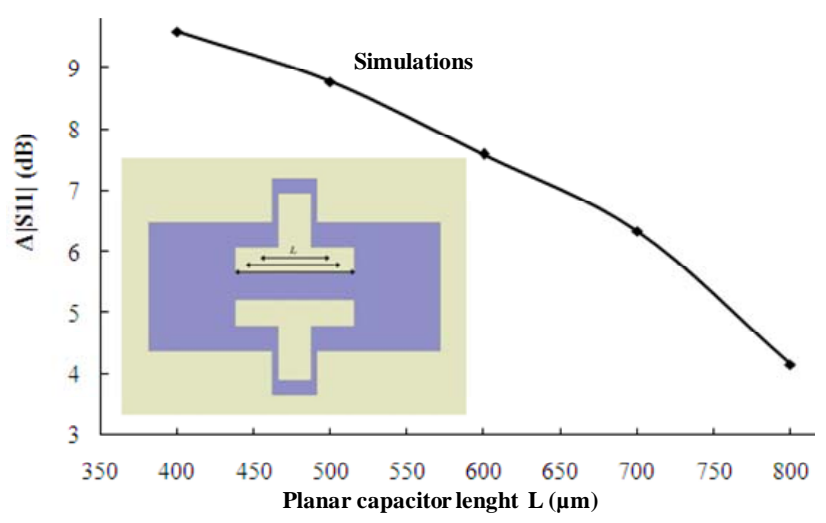

Figure 3 : S11 full-scale variation vs capacitor length $L$

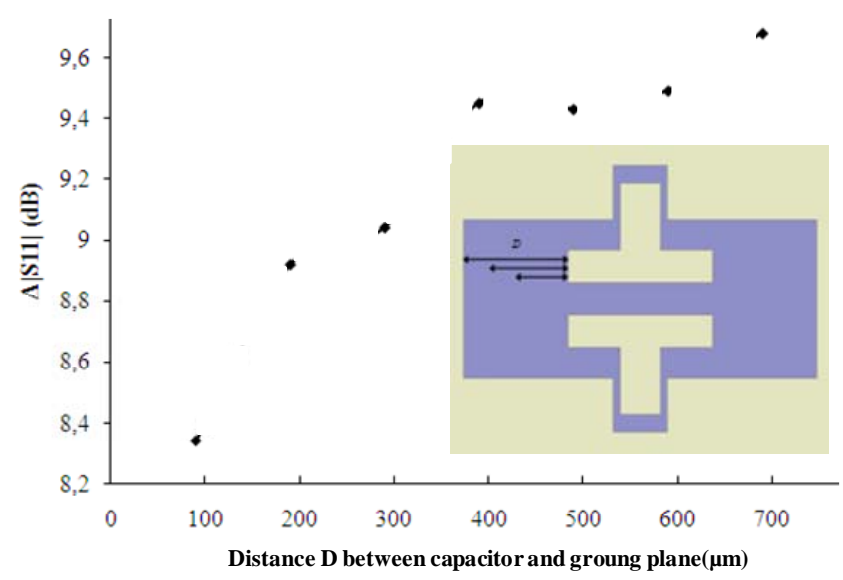

Figure 4 : S11 full-scale variation versus capacitorground distance

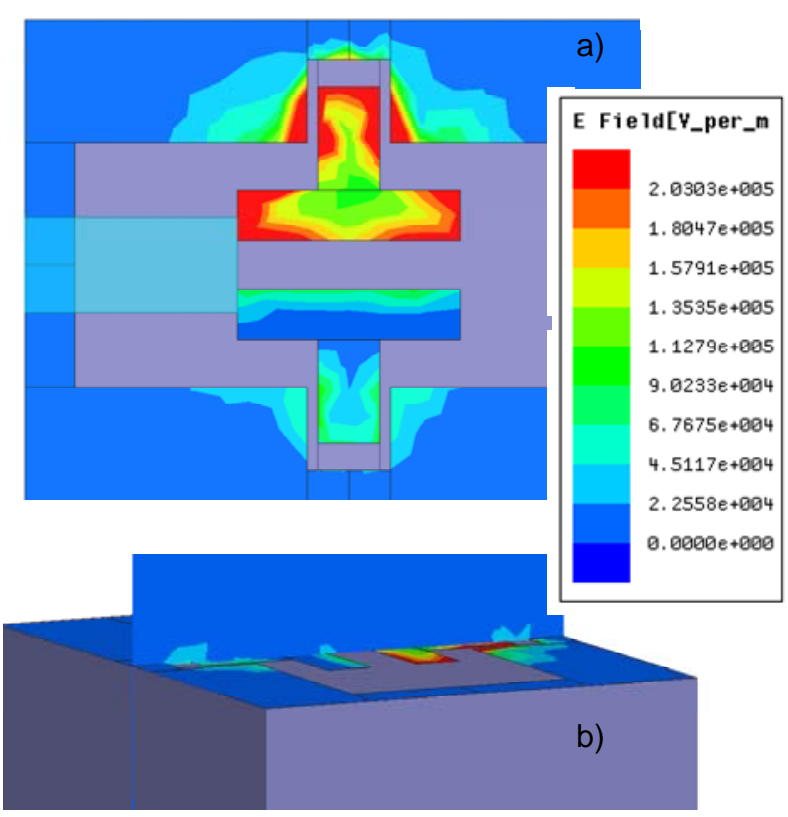

Figure 5 : Electric field distribution a) Capacitor surface and b) Vertical axis inside the channel - Without water

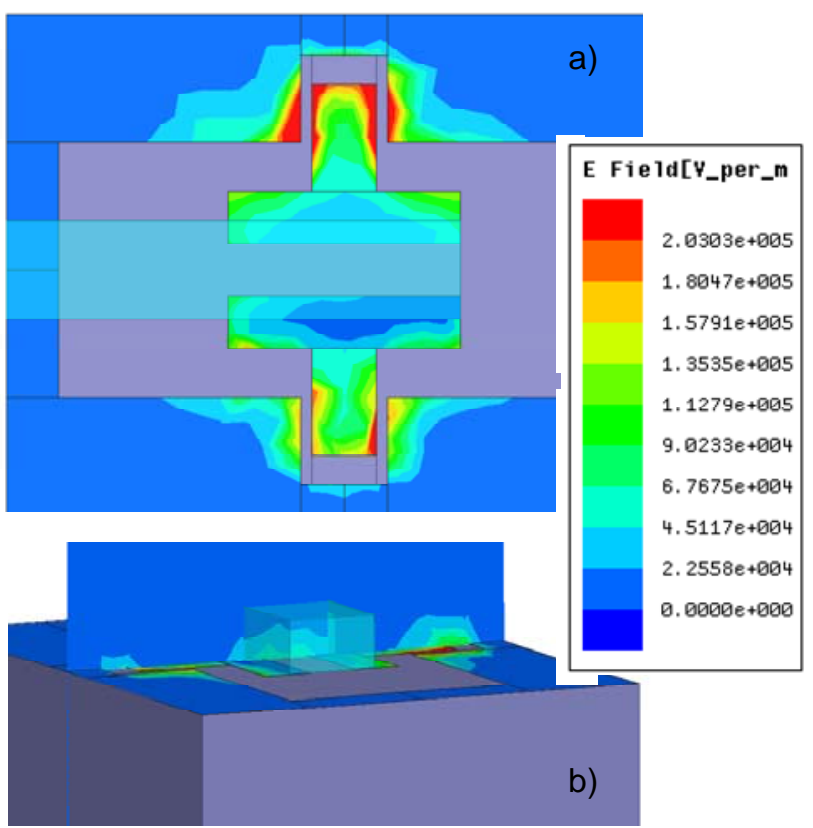

Figure 6 : Electric field distribution a) Capacitor surface and b) Vertical axis inside the channel - 100\% water

\section{TRANSDUCER FABRICATION}

The fabrication process flow requires three masks level. A $1 \mathrm{~mm}$ thick glass substrate is first metalized with $\mathrm{Ti} / \mathrm{Cu}(0.1 \mu \mathrm{m} / 0.1 \mu \mathrm{m})$ layers on the two wafer sides. The metal layer on the backside will act as a ground plane and the planar capacitor in the top side is patterned using lift off process.

A SU8 micro-channel is then fabricated above the capacitor with the following process: AP300 adhesion 
promoter, $100 \mu \mathrm{m}$ thick 3050-SU8 (spin-on 1450rpm, annealing at $65^{\circ} \mathrm{C}$ during $1 \mathrm{mn}+$ thermal ramp $10^{\circ} \mathrm{C} / \mathrm{mn}$ up to $95^{\circ} \mathrm{C}+95^{\circ} \mathrm{C}$ during $44 \mathrm{mn}$ ), SU8 patterning (photolithography with UV $365 \mathrm{~nm}$ at $20 \mathrm{~mW} / \mathrm{cm} 2$ during $24 \mathrm{~s}$, post bake exposure $1 \mathrm{mn}$ at $65^{\circ} \mathrm{C}+$ thermal ramp $10^{\circ} \mathrm{C} / \mathrm{mn}$ up to $95^{\circ} \mathrm{C}+95^{\circ} \mathrm{C}$ during $3 \mathrm{mn}$, developing with PGMEA during $15 \mathrm{mn}$, isopropanol rinse), lamination of $50 \mu \mathrm{m} 3050-$ SU8 dry film (lamination of $150 \mu \mathrm{m}$ thick PET on silicon, centrifugation of $50 \mu \mathrm{m}$ thick SU8, annealing same as above except $95^{\circ} \mathrm{C}$ during $27 \mathrm{mn}$ instead of $44 \mathrm{mn}$, oxygen plasma at $200 \mathrm{~W}$ during 30 s for SU8 on glass substrate, lamination at $1 \mathrm{~m} / \mathrm{mn}$ with $65^{\circ} \mathrm{C}$ and 2bars), peeling to remove silicon holder, SU8 patterning to open fluidic access.

In the next step one fluidic access is sealed from the tank side with a square piece of glass and double-sided adhesive. Finally the second access is used to fill the structure and is placed in a container filled with liquid and placed under vacuum. The fluid is then forced into the SU-8 micro-structure using atmospheric pressure. The liquid positioning is performed thanks to evaporation.

A capacitor view before liquid filling is given in Figure 7.

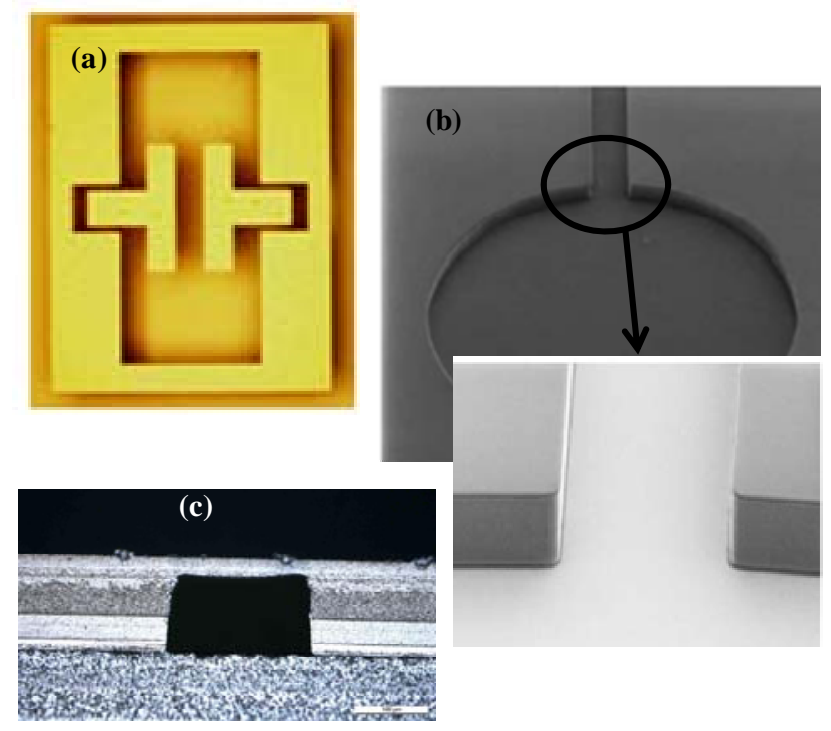

Figure 7 : Photography of microfluidic capacitor (a) top view, (b) zoom on SU8 channel, (c) SU8 channel cross section

\section{TRANSDUCER CHARACTERIZATION}

The micro-fluidic part has been first characterized by measuring the shift of the water level $\left(\Delta \mathrm{L}_{\mathrm{c}}\right)$ inside the channel for temperature between $24^{\circ} \mathrm{C}$ and $33^{\circ} \mathrm{C}$ (Figure 9). The full temperature range of $9^{\circ} \mathrm{C}$ corresponds to the two extreme positions of the water level relative to beginning and end of capacitor electrode. The sensitivity is around $43 \mu \mathrm{m} /{ }^{\circ} \mathrm{C}$ with a good correlation between measurements and models, taking into account the non linear expansion coefficient of water (Figure 8, Figure 10).
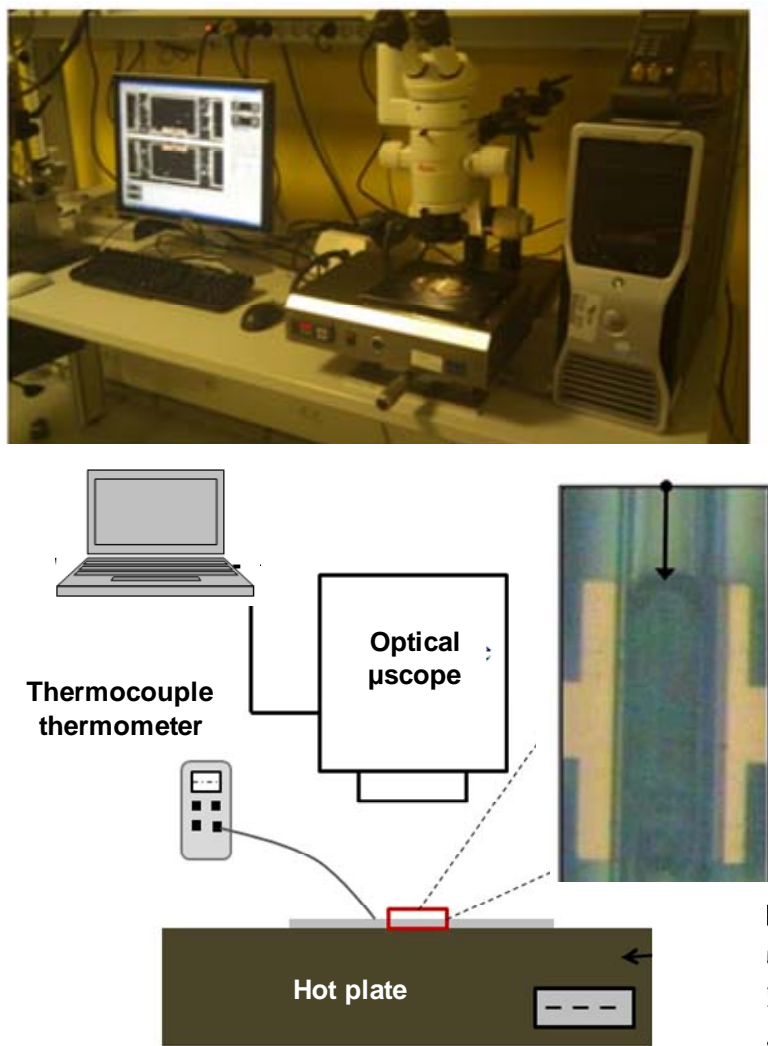

Figure 8: View of micro-fluidic setup ${ }^{\circ}$

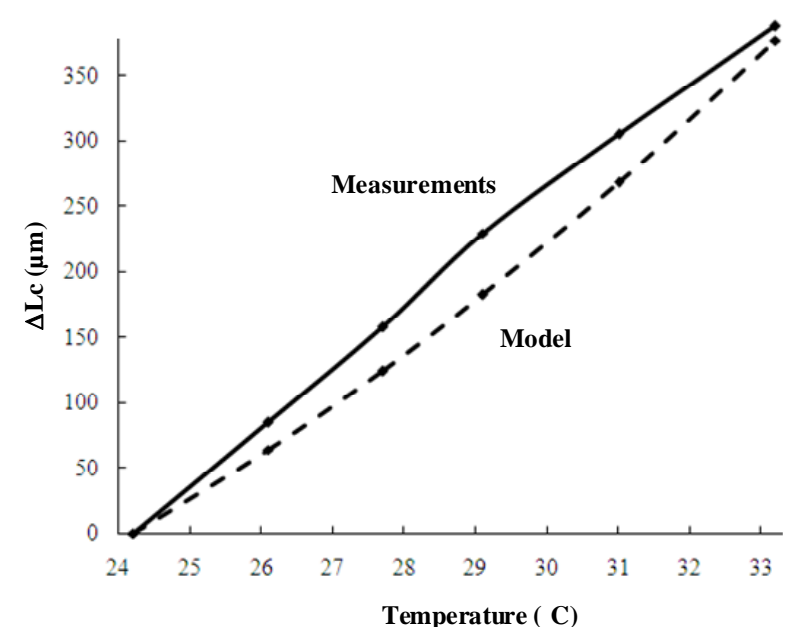

Figure 9: Shift of water front inside channel versus $T^{\circ}$ 


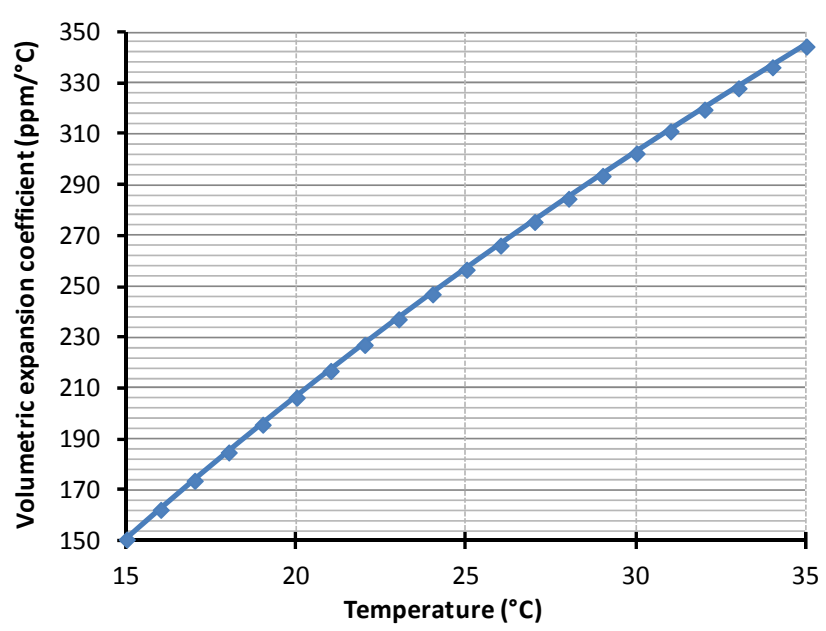

Figure 10: Volumetric expansion coefficient of water versus $T^{\circ}$

On wafer RF measurements have been performed between $20 \mathrm{GHz}$ and $40 \mathrm{GHz}$ using vector network analyser. The full scale variation versus temperature is around $8 \mathrm{~dB}$ at $29.75 \mathrm{GHz}$ (Figure 11). Extraction of capacitance value with electrical model gives a capacitance shift between $20 \mathrm{fF}$ and $140 \mathrm{fF}$ for the full scale.

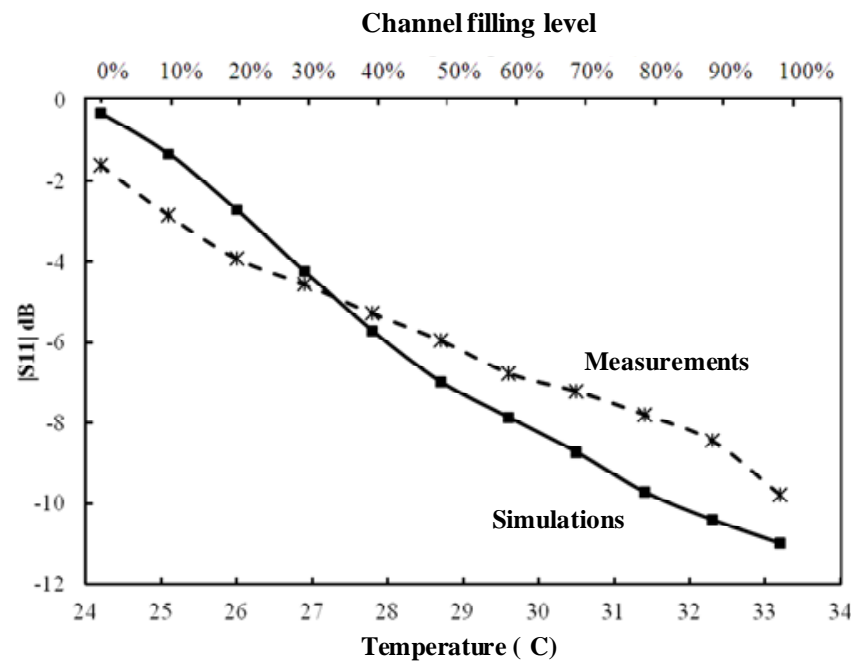

Figure 11 : Reflection coefficient of capacitor versus channel filling level with water

\section{TEST OF OTHERS LIQUIDS}

Preliminary tests have been also done by replacing the water by ethylene or propylene glycol in order to solve the problem of water evaporation. Figure 12 gives the reflection coefficient S11 versus frequency for different configurations. We can see that with pure ethylene or propylene glycol, the S11 full scale variation at $29.75 \mathrm{GHz}$ is two low (less than $1 \mathrm{~dB}$ ). By mixing water with ethylene or propylene glycol (50\%/50\%), the S11 full scale variation at $29.75 \mathrm{GHz}$ is increased up to $6 \mathrm{~dB}$.

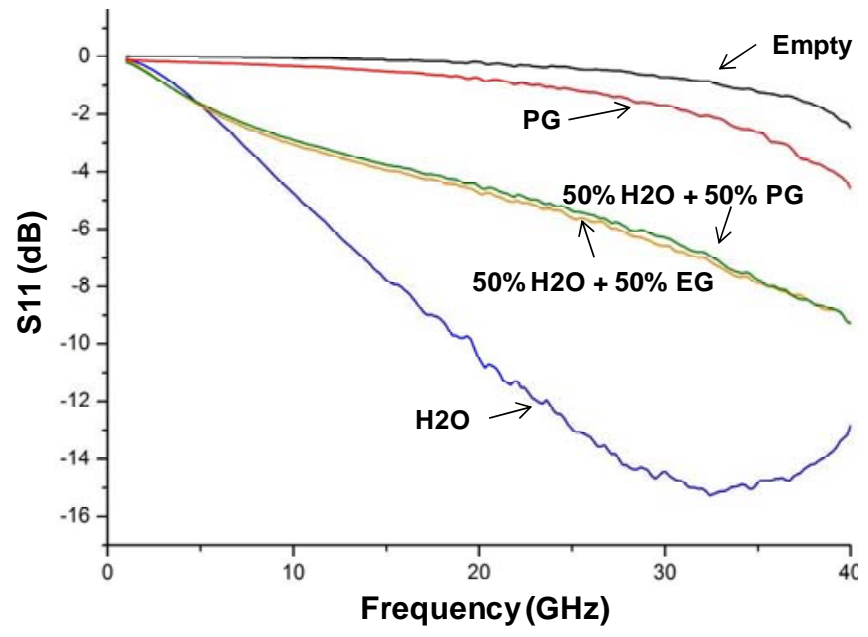

Figure 12 : Reflection coefficient versus frequency for various liquids inside the channel (PG : propylene glycol, EG : ethylene glycol)

\section{CONCLUSIONS}

We have shown that the electromagnetic coupling between dielectric fluid as water and an RF capacitor allow obtaining a high sensitivity for wireless passive temperature sensors. Studies should be pursued in order to replace the water by another liquid that has no evaporation problems. First results obtained with ethylene or propylene glycol confirm that a compromise between high sensitivity and technological constraints can be done.

\section{REFERENCES}

[1] A. Mahmood et al., "An Evanescent-mode Cavity Resonator Based Thermal Sensor,” IEEE Sensors, Oct 2007, Atlanta, USA

[2] S. Scott, D Peroulis, “A Capacitively-Loaded MEMS Slot Element for Wireless $T^{\circ}$ Sensing,” IEEE MTT-S, June 2009 , Boston, USA

[3] T. Thai et al., "Novel Passive Wireless Ultrasensitive RF Temperature Transducer,” IEEE Sensor Journal, Vol. 12, Issue 8, sept 2012

[4] C. Mandel et al., "Passive Wireless Temperature Sensing with BST-Based Chipless Transponder," 6th German Microwave Conference, 14-16 March 2011, Darmstadt, Germany

[5] H. Cheng et al., "Wireless Passive $T^{\circ}$ Sensor Using Resonator/Antenna Integration,” IEEE Ant. \& Wireless Prop. Letters, Vol. 11, 2012

[6] A. Traille et al., "Wireless Passive Temperature Sensor Utilizing Microfluidic Principles," IEEE Sensors, Oct 2011, Limerick, Ireland

[7] S. Bouaziz et al., "Micro-fluidic Temperature sensor for wireless passive radar interrogation," IEEE sensors 2012, Oct 2012, Taipei, Taiwan

\section{CONTACT}

P. PONS, tel: +33-5-61-33-64-63; ppons@laas.fr 